Article

\title{
Tunable Metamaterial with Gold and Graphene Split-Ring Resonators and Plasmonically Induced Transparency
}

\author{
Qichang Ma, Youwei Zhan and Weiyi Hong * \\ Guangzhou Key Laboratory for Special Fiber Photonic Devices and Applications \& Guangdong Provincial Key \\ Laboratory of Nanophotonic Functional Materials and Devices, South China Normal University, \\ Guangzhou 510006, China; qichangma@m.scnu.edu.cn (Q.M.); zhanyw@m.scnu.edu.cn (Y.Z.) \\ * Correspondence: hongwy@m.scnu.edu.cn; Tel.: +86-185-203-89309
}

Received: 28 November 2018; Accepted: 20 December 2018; Published: 21 December 2018

\begin{abstract}
In this paper, we propose a metamaterial structure for realizing the electromagnetically induced transparency effect in the MIR region, which consists of a gold split-ring and a graphene split-ring. The simulated results indicate that a single tunable transparency window can be realized in the structure due to the hybridization between the two rings. The transparency window can be tuned individually by the coupling distance and/or the Fermi level of the graphene split-ring via electrostatic gating. These results could find significant applications in nanoscale light control and functional devices operating such as sensors and modulators.
\end{abstract}

Keywords: metamaterials; mid infrared; graphene split-ring; gold split-ring; electromagnetically induced transparency effect

\section{Introduction}

Electromagnetically-induced transparency (EIT) is a concept originally observed in atomic physics and arises due to quantum interference, resulting in a narrowband transparency window for light propagating through an originally opaque medium [1,2]. The EIT effect extended to classical optical systems using plasmonic metamaterials leads to new opportunities for many important applications such as slow light modulator [3-6], high sensitivity sensors [7,8], quantum information processors [9], and plasmonic switches [10-12]. Generally speaking, the realization of the EIT effect is usually achieved by two kinds of schemes such as the bright-bright mode coupling [7,12-16] and the bright-dark mode coupling [17-21]. So far, many researches have obtained the EIT effect from various metamaterial structures [11,22-27]. However, most of them only consist of metallic materials and they can only be controlled by the geometry of structures, which limits their applications.

Graphene is a two-dimensional material which is composed of single layer of carbon atoms, which has been widely used in optoelectronic devices, such as optical modulators [28-30] due to its unique properties such as high electron mobility [31], high light transparency [32] and high thermal conductivity [33]. Particularly, the surface conductivity of graphene has a wide range of tunable characteristics by changing the Fermi level of the graphene via electrostatic gating, which makes it a significant potential application in high-performance tunable optical devices [34,35]. Meanwhile, graphene is widely used in metamaterial to achieve a variety of optoelectronic devices with tunable properties [36-38].

Recently, L.S. Yan et al. have investigated that a plasmonic waveguide system based on side coupled complementary split-ring resonators and the electromagnetic responses of CSRR can be flexibly handled by changing the asymmetry degree of the structure and the width of the metallic 
baffles [39]. W. Yu et al. have realized a dual-band EIT effect which was composed of a split-ring resonator (SRR) and a pair of metal strips. Most of the previous researches were based on metallic split-ring which lacks tunability [40]. In this paper, we propose a periodic metamaterial structure which is composed of a graphene split-ring and a gold split-ring to investigate the EIT effect in the MIR regions. A transparency window can be observed in the transmission spectrum of the structure under plane wave excitation. It is found that the coupling strength greatly depends on the separation between the two rings. Besides, the EIT window can be tuned by changing the Fermi levels of the graphene split-ring via electrostatic gating, which may offer possible applications at tunable mid-infrared functional devices, such as optical switches and modulators.

\section{Materials and Methods}

As shown in Figure 1a, the metamaterial structure used to demonstrate the EIT phenomenon consists of three layers. The top layer is composed of gold split-ring and graphene split ring while the middle layer plays a role as a substrate and its material is $\mathrm{Al}_{2} \mathrm{O}_{3}$ and the graphene split-ring is composed of 5 layers of graphene in our following simulations so as to enhance the modulation depth [41]. The bottom layer is doped silicon (doped Si) substrate which is used for an electrode to apply voltage to the graphene split-ring for changing its Fermi level, and another electrode is $A u_{1}$ whose material is gold as shown in Figure 1a. In the simulation of the transmission spectra, $A u_{1}$ is negligible because of the relatively small size with respect to the structure. The incident light propagates in the $\mathrm{z}$ direction and its polarization is along $\mathrm{x}$ direction. Both the gold split-ring and graphene split-ring are symmetric in y direction and their symmetry axis are coinciding. The (complex) refractive index of $\mathrm{Al}_{2} \mathrm{O}_{3}$ is obtained from Table I, page 662 in Ref. [42] and the doping concentration of doped $\mathrm{Si}$ is $10^{18} \mathrm{~cm}^{-3}$ and its refractive index can be obtained from Ref. [43]. Both the $\mathrm{Al}_{2} \mathrm{O}_{3}$ and doped Si have been considered having the dispersion and absorption effects in our simulations.

The optical properties of the gold material are obtained from Palik's experimental data. The surface complex conductivity of graphene $\sigma(\omega)$ is dominated by interband and intraband transitions within the random-phase approximation, which can be calculated as [44,45]:

$$
\sigma(\omega)=\sigma_{\text {interband }}+\sigma_{\text {intraband }}
$$

where

$$
\begin{gathered}
\sigma_{\text {interband }}=\frac{e^{2}}{4 \hbar}\left\{\frac{1}{2}+\frac{1}{\pi} \arctan \left(\frac{\hbar \omega-2 E_{f}}{2 k_{B} T}\right)-\frac{i}{2 \pi} \ln \left(\frac{\left(\hbar \omega+2 E_{f}\right)^{2}}{\left(\hbar \omega-2 E_{f}\right)^{2}+\left(2 k_{B} T\right)^{2}}\right)\right\} \\
\sigma_{\text {intraband }}=\frac{2 i e^{2} k_{B} T}{\pi \hbar^{2}\left(\omega+i \tau^{-1}\right)} \ln \left(2 \cosh \left(\frac{E_{f}}{2 k_{B} T}\right)\right)
\end{gathered}
$$

Here, $\omega$ is the optical angular frequency, $T$ is the ambient temperature ( $300 \mathrm{~K}$ in this paper), $E_{f}$ is the Fermi level of graphene, $h=h / 2 \pi$ is the reduced Plank's constant, $k_{B}$ is the Boltzmann constant, $\tau$ is the carrier relaxation time and $\tau=\hbar / 2 \Gamma$ [46], where $\Gamma$ is the scattering rate and it is set 0.00099 $\mathrm{eV}$ in this paper (corresponding to the carrier relaxation time $\tau \approx 0.33 \mathrm{ps}$ ). It can be seen from the above formula that the surface conductivity is greatly affected by the Fermi level and the Fermi level is determined by the carrier concentration $n_{g}$ and Fermi velocity $V_{f}$. The formula $E_{f}=\hbar V_{f}\left(\pi n_{g}\right)^{1 / 2}$ with the Fermi velocity of $V_{f}=10^{6} \mathrm{~m} / \mathrm{s}$ can be obtained from Ref. [47] and $n_{g}=\varepsilon_{0} \varepsilon_{d} V_{g} / e H_{1}$, where $V_{g}$ is the applied voltage and $\varepsilon_{d}$ is the permittivity of $\mathrm{Al}_{2} \mathrm{O}_{3}$ and $\mathrm{H}_{1}$ is the thickness of $\mathrm{Al}_{2} \mathrm{O}_{3}$. In the following simulation, graphene is modeled as a thin anisotropic material film and the in-plane permittivity is approximated to be [44]:

$$
\varepsilon_{g}=1+\frac{i \sigma(\omega)}{\varepsilon_{0} \omega t_{g}}
$$


where $t_{g}$ is the thickness of graphene which is estimated as $1 \mathrm{~nm} \mathrm{[48]} \mathrm{and} \varepsilon_{0}$ is the permittivity in vacuum. In addition, the conductivity of the $\mathrm{N}$-layer graphene is $\mathrm{N} \sigma[49,50]$.

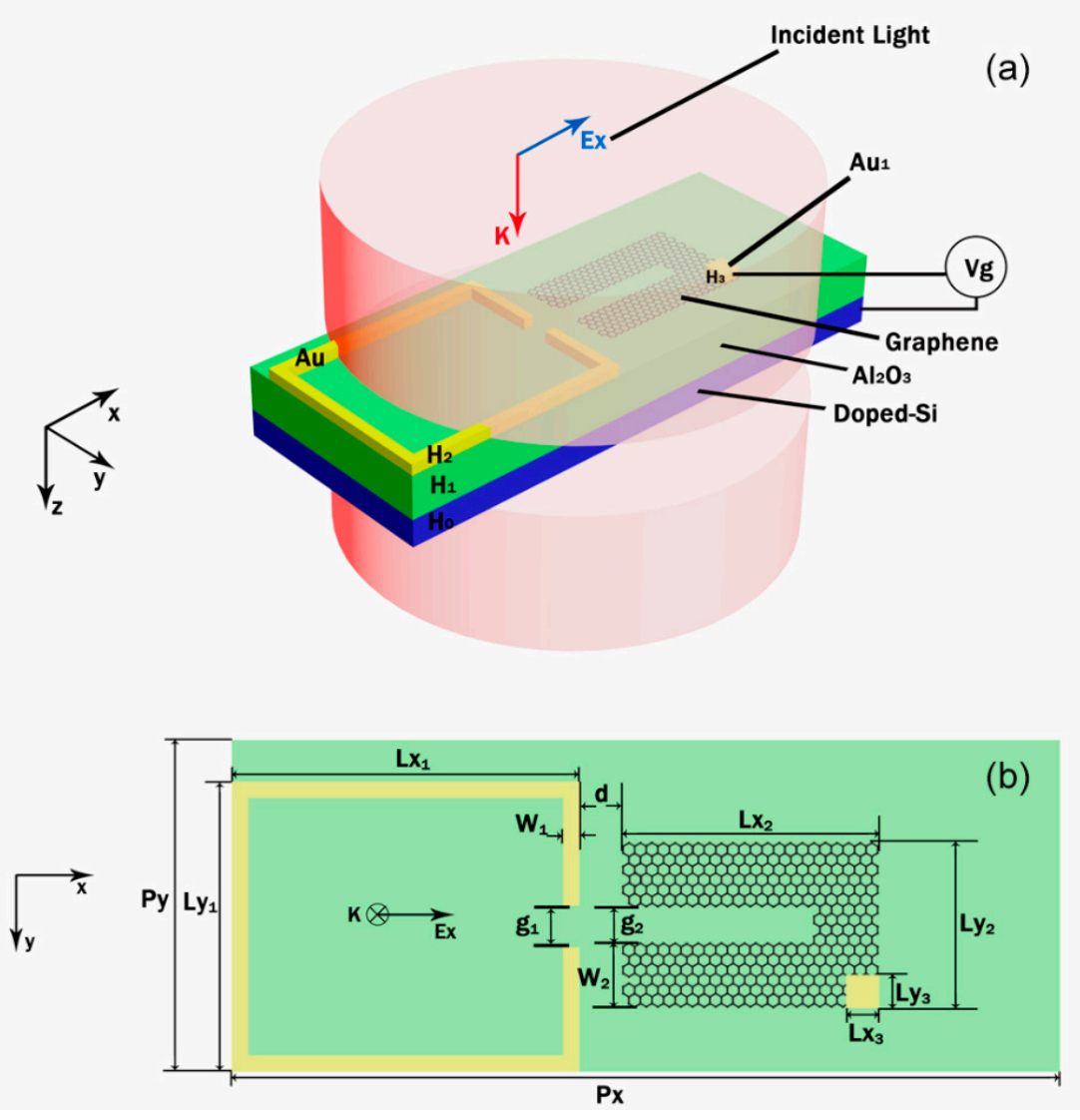

Figure 1. (a) Schematic diagram of the plasmonic metamaterial unit cell consists of a graphene split-ring and a gold split-ring. (b) Top view of metamaterial structure. The periods of the $y$ and $x$ direction are $\mathrm{Py}=0.22 \mu \mathrm{m}, \mathrm{Px}=1.34 \mu \mathrm{m}$, respectively. The distance between the graphene split-ring and the gold split-ring is $d$ and the gaps of the gold split-ring and the graphene split-ring are $\mathrm{g}_{1}=8 \mathrm{~nm}, \mathrm{~g}_{2}=20 \mathrm{~nm}$, respectively. The width of the gold split-ring and the graphene split-ring are $W_{1}=12 \mathrm{~nm}, W_{2}=43 \mathrm{~nm}$. The length of the gold split-ring in the $y$ and $x$ direction are $\mathrm{Ly}_{1}=200 \mathrm{~nm}, \mathrm{Lx}_{1}=262 \mathrm{~nm}$, respectively; and the length of the graphene split-ring in the $y$ and $x$ direction are $\mathrm{Ly}_{2}=106 \mathrm{~nm}, \mathrm{Lx}_{2}=104 \mathrm{~nm}$, respectively. The thickness of doped silicon, $\mathrm{Al}_{2} \mathrm{O}_{3}$ and $\mathrm{Au}$ are set as $\mathrm{H}_{0}=10 \mathrm{~nm}, \mathrm{H}_{1}=40 \mathrm{~nm}$ and $\mathrm{H}_{2}=4 \mathrm{~nm}$, respectively. $V_{g}$ is the applied voltage and both the $\mathrm{Au}_{1}$ and doped silicon are served as electrodes to apply voltages to the graphene split-ring. The thickness of the $\mathrm{Au}_{1}$ is $\mathrm{H}_{3}=4 \mathrm{~nm}$ and its width $\left(\mathrm{Ly}_{3}\right)$ and length $\left(\mathrm{Lx}_{3}\right)$ are set as $10 \mathrm{~nm}$.

In this paper, we use the finite-difference time-domain (FDTD) simulations to numerically investigate the properties of the structure. The perfectly matched layer (PML) absorbing boundary conditions are set on the $\mathrm{z}$ direction while the periodic boundary conditions are set on the $\mathrm{x}$ and y directions.

\section{Results and Discussion}

To demonstrate the EIT effect, we numerically calculate the simulated transmission spectra of the unit cell with the graphene split-ring and the gold split-ring are shown in Figure 1a. The plasmonic resonances of the graphene split-ring and the gold split-ring are excited at the same wavelength. In addition, the transmission spectra of the unit cell with a graphene split-ring and a gold split-ring under x-polarized and y-polarized incident light excitation, respectively. It is obviously that when 
using the x-polarized incident light, a transparency window is observed. For the case of y-polarized incident light, there are two plasmon resonance peaks at $3.61 \mu \mathrm{m}$ and $7.19 \mu \mathrm{m}$ observed and no EIT phenomenon can be found. Consequently, we choose $x$-polarized incident light in the following simulations. In the simulations, the $E_{f}$ of the graphene split-ring is set as $0.9 \mathrm{eV}$ and the coupling distance $d$ is $20 \mathrm{~nm}$. From the transmission spectra in Figure 2a, one can find that a strong plasmon resonance at $4.09 \mu \mathrm{m}$ of both the graphene split-ring and the gold split-ring can be excited by the $\mathrm{x}$-polarized incident light. The quality factor of graphene split-ring is higher than that of the gold split-ring and a transparency window with 95\% transmission appears at $3.95 \mu \mathrm{m}$ when we put the two rings together due to the interaction of them. In addition, two obvious dips can be found in the transmission spectra (orange line in Figure $2 \mathrm{~b}$ ) at $3.83 \mu \mathrm{m}$ and $4.35 \mu \mathrm{m}$, respectively.
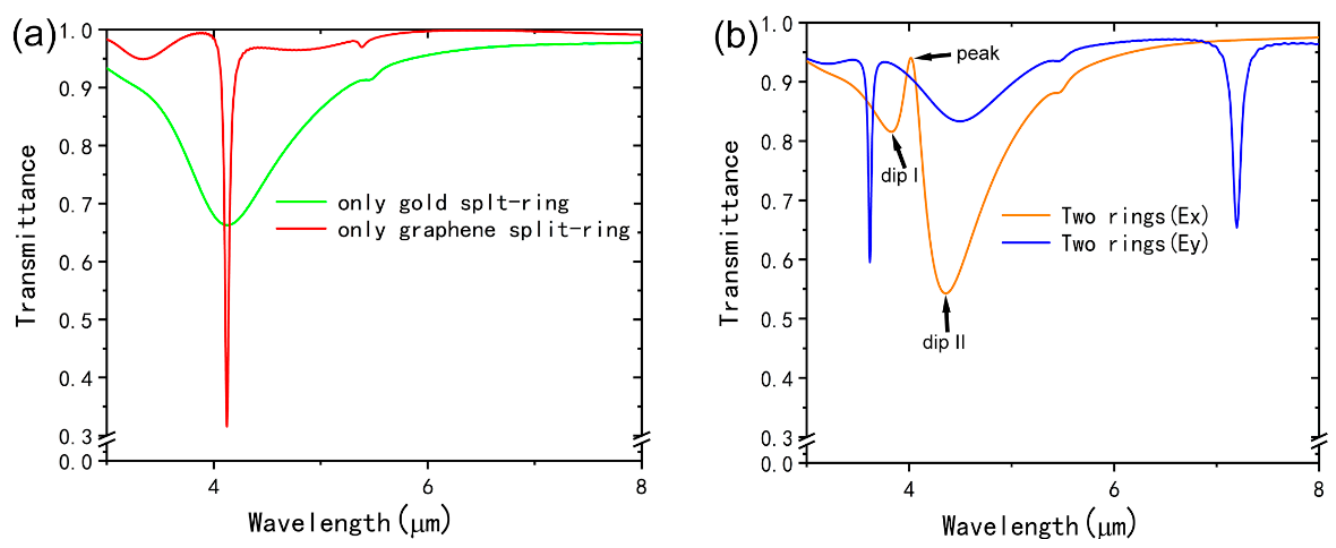

Figure 2. (a) Transmission spectra of the individual graphene split-ring and the individual gold split-ring. (b) Transmission spectra of the structure consists of graphene split-ring and gold split-ring under x-polarized and y-polarized incident light excitation, respectively.

Then, we study the response of EIT effect resulting from the variation of the layers of graphene split-ring (Figure 3a) and the periods in the $x$ direction the total structure. The Fermi level is set as $0.9 \mathrm{eV}$ and the distance of the two split-rings $d$ is $20 \mathrm{~nm}$. It can be observed that dip II is obviously blue-shifted from $7.97 \mu \mathrm{m}$ to $4.35 \mu \mathrm{m}$ while dip I blue-shifts slightly and its transmittance increases with the layers of the graphene split-ring $\mathrm{N}$ increasing from 1 to 5 . In addition, it is clear shown that the transmission peak is blue-shifted and the line width of the transmission peak becomes smaller and narrower. This is because the hybridized of the gold split-ring and graphene split-ring become stronger with increasing the layer number $\mathrm{N}$. It is also found that 4 layers or 5 layers of the graphene split-ring are suitable. Here we choose the graphene split-ring of 5 layers because the quality factor of transmission peak is larger than that of the 4 layers. In Figure $3 b$, it is shown that the period in the $x$ direction of the plasmonic metamaterial unit cell can also influence the EIT phenomenon. With the increase of the Px from $1.34 \mu \mathrm{m}$ to $2.34 \mu \mathrm{m}$, both dip I and dip II blue-shift slightly and the amplitudes of the transmittance increase. The line width of the transmission peak becomes larger and its transmittance increase with increasing the periods $(\mathrm{Px})$ in the $\mathrm{x}$ direction. 

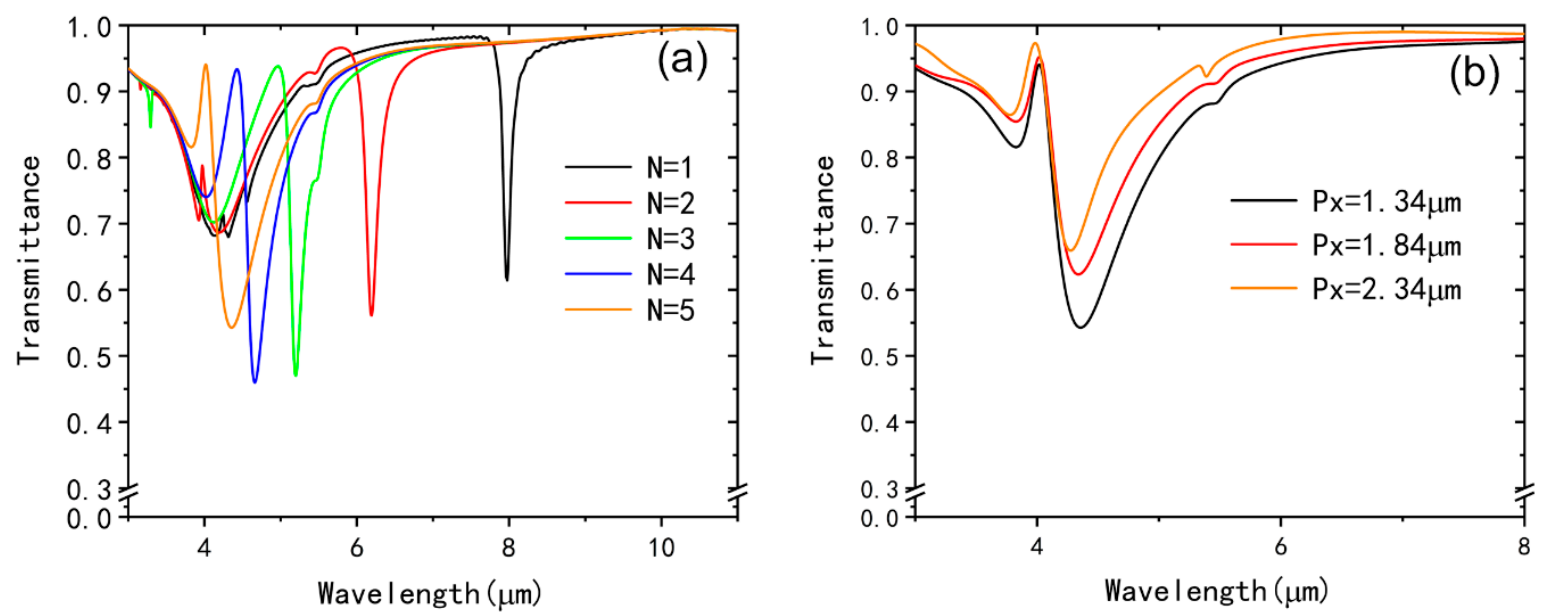

Figure 3. (a) Transmission spectra of the individual graphene split-ring with different layers. (b) Transmission spectra of the structure with different periods (Px) in the $\mathrm{x}$ direction.

Furthermore, we also investigate the dependence of the EIT spectra on the distance $d$ between the two rings. As shown in Figure 4, the EIT peak gradually becomes sharper and its transmittance gradually decreases with the increasing of $d$. When $d$ comes to $400 \mathrm{~nm}$, the peak will disappear. It reveals that the interaction of gold split-ring and graphene split-ring becomes weaker and their interaction eventually disappears when the coupling distance is large enough. It can also find that dip I red-shifts slightly while the dip II blue-shifts with the increase of $d$ and both their transmittance decrease. Therefore, the coupling strength of the metamaterial structure greatly depends on the distance of the gold split-ring and graphene split-ring.

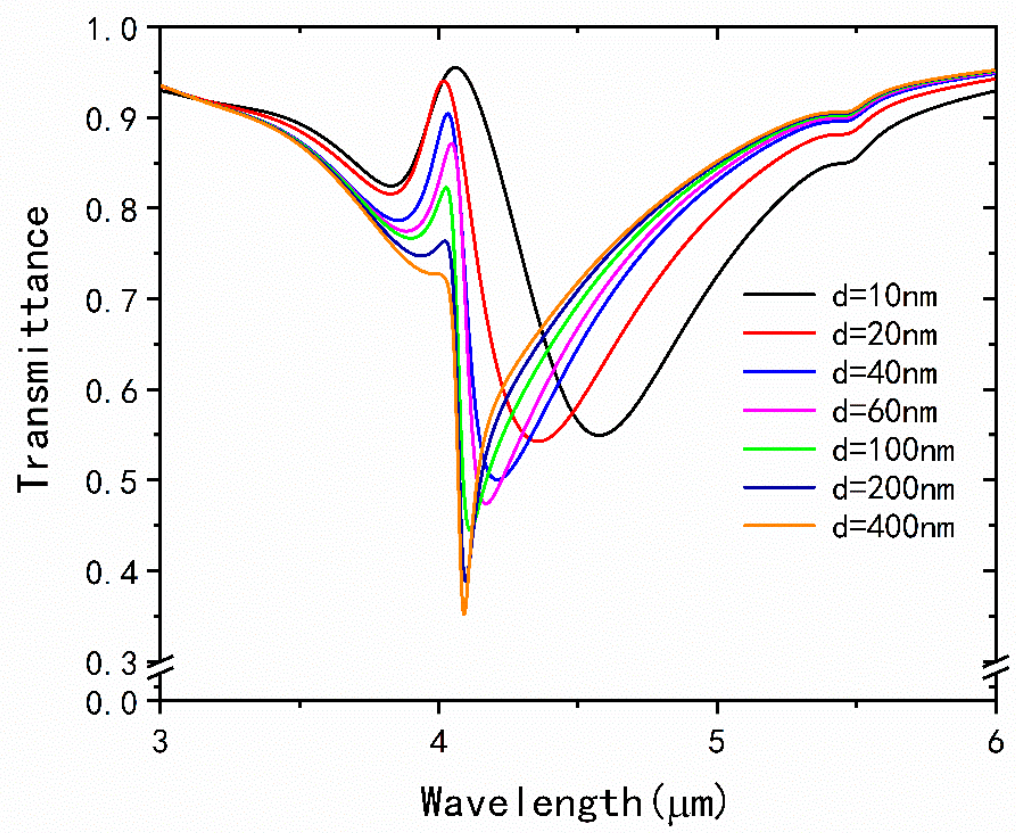

Figure 4. Transmission spectra of the metamaterial structure with different distances $d$.

To get further insight into the physics of the EIT phenomenon of our structure, the electric-field distributions of the z-component at wavelength I $(\lambda=3.83 \mu \mathrm{m})$ and wavelength II $(\lambda=4.35 \mu \mathrm{m})$ are shown in Figure 5a-d. The generation of dip I and dip II can be understood and predicted by the plasmon hybridization model, similar to the case for the molecular orbital theory and plasmon hybridization model [51-54]. Since the thicknesses of the graphene split-ring and the gold split-ring are 
different, we place two power monitors at $2 \mathrm{~nm}$ above the graphene split-ring and the gold split-ring, respectively. In this simulation, the distance $d$ is $20 \mathrm{~nm}$, and the Fermi level of graphene split-ring is $0.9 \mathrm{eV}$.

(a)

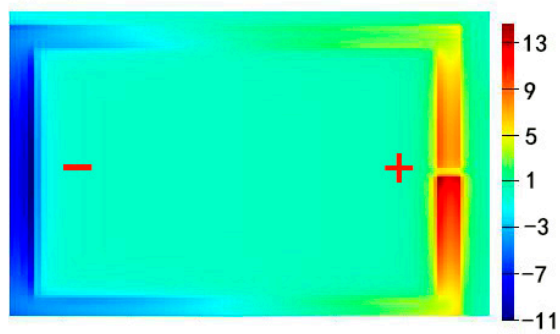

(C) $\lambda=4.35 \mu \mathrm{m}$ Gold split-ring

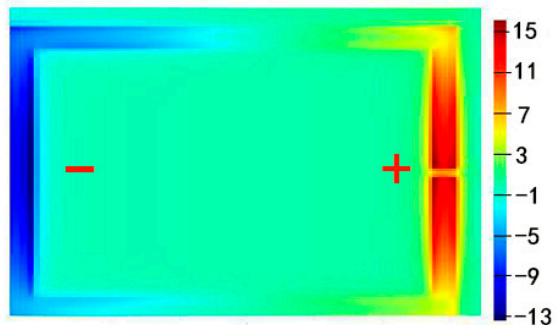

(b) $\quad \lambda=3.83 \mu \mathrm{m}$ Graphene split-ring

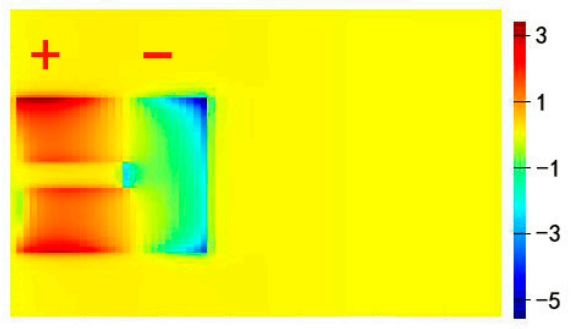

(d) $\quad \lambda=4.35 \mu \mathrm{m}$ Graphene split-ring

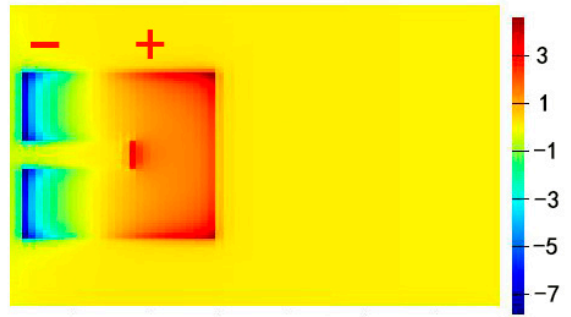

Figure 5. z-component distributions of the electric field under $x$-polarized continue light excitation at (a) $\lambda=3.83 \mu \mathrm{m}$ (Au power monitor), (b) $\lambda=3.83 \mu \mathrm{m}$ (graphene power monitor), (c) $\lambda=4.35 \mu \mathrm{m}$ (Au power monitor), (d) $\lambda=4.35 \mu \mathrm{m}$ (graphene power monitor).

The placement of graphene split-ring and gold split-ring can be treated as asymmetric nanoparticle dimer which has been investigated in Ref. [53]. When $d$ is small enough, their local surface plasmons will couple to each other, which is analogous to $\sigma$ hybridization of $p$ orbital electron in the atomic outer layer. From Figure 5a,b, one can observe that the left side of the gold split-ring gathers a large amount of negative induced charge, and a large amount of positive induced charges are accumulated on the right side for the case of $\lambda=3.83 \mu \mathrm{m}$. In contrast, the positive and negative induced charges are distributed on the left and right sides of the graphene split-ring. The different charge distributions of the two rings are similar to the anti-bonding mode of the hybrid molecular system. On the other hand, one can find that the distribution of induced change in the gold split-ring remains unchanged at the wavelength $\lambda=4.35 \mu \mathrm{m}$, while the distribution of induced change in the graphene split-ring is opposite to the situation at $\lambda=3.83 \mu \mathrm{m}$ from Figure $5 \mathrm{c}, \mathrm{d}$, which is similar to the bonding mode of hybrid molecular system.

As mentioned earlier, the complex surface conductivity of graphene can be changed by controlling its Fermi level, which can be realized by applying different gate-voltages to the graphene split-ring. Compared with the reported bright-bright mode coupling EIT structure fabricated by metallic material, we can realize the dynamically control of the EIT window in our metamaterial structure without reconstructing the geometries or imbedding other actively controlled materials. Figure 6a illustrates the transmission spectra with different Fermi levels, it is apparent that the EIT window can be tuned over a large range in the MIR regions by a small change of the Fermi level. When the Fermi level changes from $0.6 \mathrm{eV}$ to $0.9 \mathrm{eV}$, the transmission window blue-shifts from $4.82 \mu \mathrm{m}$ to $4.02 \mu \mathrm{m}$, which can be interpreted by the graphene plasmonic resonance wavelength $\lambda \sim 1 / E_{f}^{1 / 2}$ [55]. At the same time, the transmittance of the dip I and dip II will decrease with increasing of the Fermi level while the transmittance of the peak almost remains unchanged. The transmission spectra of the unit cell with only graphene split-ring with different Fermi level are shown in Figure 6b. When the Fermi level 
changes from $0.6 \mathrm{eV}$ to $0.9 \mathrm{eV}$, the resonance wavelengths blue shift from $4.99 \mu \mathrm{m}$ to $4.12 \mu \mathrm{m}$ and the amplitude of the transmittance are decreasing. It is easy to find that the resonance wavelength of individual graphene split-ring in Figure 6a is almost the same as Dip II in Figure $6 \mathrm{~b}$ for the same Fermi level, which shows that the dip II is greatly affected by the graphene split-ring.
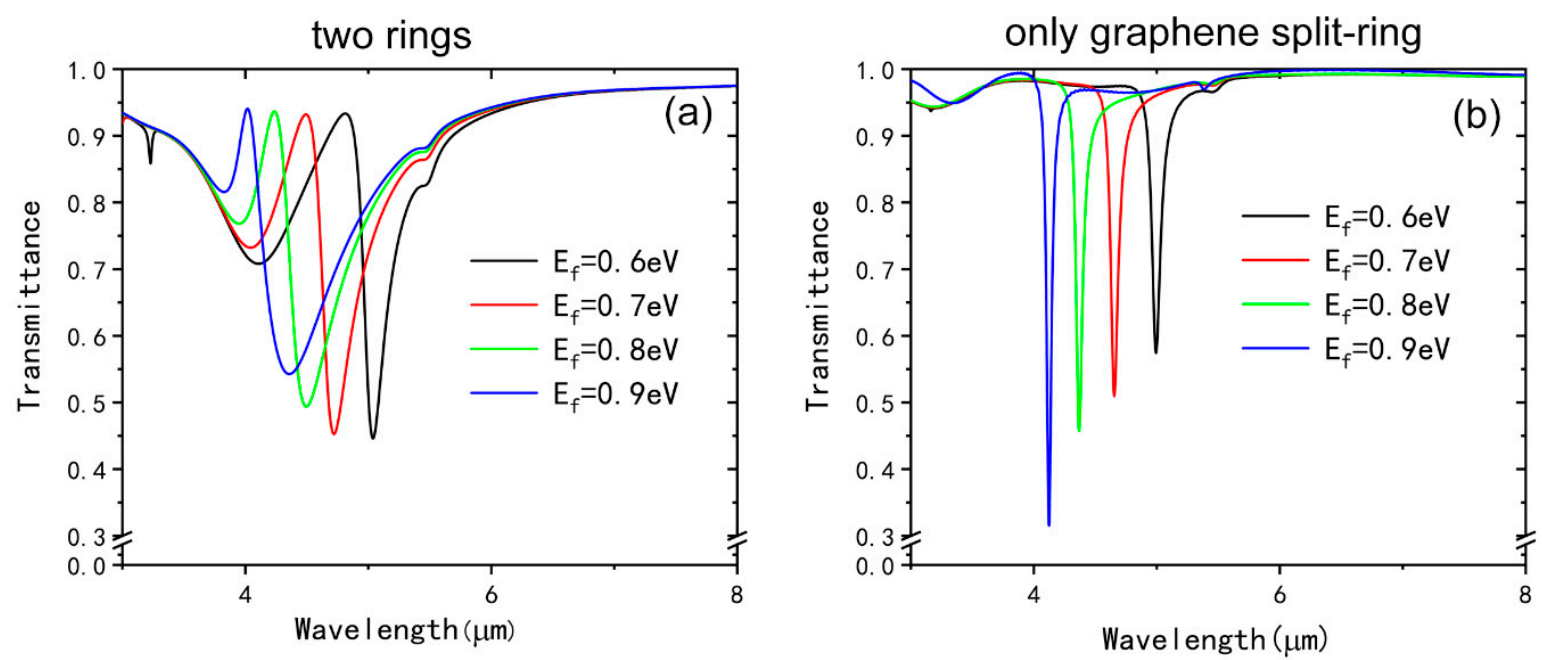

Figure 6. (a) Transmission spectra of the two rings with different Fermi levels of the graphene split-ring. (b) Transmission spectra of the individual graphene split-ring with different Fermi levels.

\section{Conclusions}

In this paper, we have successfully proposed that the EIT effect can be realized through bright-bright modes coupling in the MIR regions. The EIT window appears due to the hybridization between the gold split-ring and graphene split-ring and it is sensitive to the coupling distance. Moreover, we investigate the response of EIT effect resulting from the variation of the layers of graphene split-ring and periods in the $x$ direction. Particularly, the EIT window can be dynamically tuned by adjusting the Fermi level of the graphene split-ring instead of reconstructing the structure. These properties could lead to new opportunities for many important applications, such as sensors and slow light modulators in MIR regions.

Author Contributions: Formal Analysis, Q.M. and Y.Z.; Writing-Original Draft Preparation, Q.M. and Y.Z.; Writing-Review \& Editing, W.H.

Funding: This research was supported by the National Natural Science Foundation of China (Grant No. 11874019).

Acknowledgments: This research was supported by the National Natural Science Foundation of China (Grant No. 11874019) and Guangzhou Key Laboratory for Special Fiber Photonic Devices and Applications, South China Normal University, Guangzhou 510006, People's Republic of China.

Conflicts of Interest: The authors declare no conflict of interest.

\section{References}

1. Field, J.E.; Hahn, K.H.; Harris, S.E. Observation of electromagnetically induced transparency in collisionally broadened lead vapor. Phys. Rev. Lett. 1991, 67, 3062-3065. [CrossRef] [PubMed]

2. Boller, K.J.; Imamolu, A.; Harris, S.E. Observation of electromagnetically induced transparency. Phys. Rev. Lett. 1991, 66, 2593-2596. [CrossRef] [PubMed]

3. Zhu, L.; Meng, F.-Y.; Fu, J.-H.; Wu, Q.; Hua, J. Multi-band slow light metamaterial. Opt. Express 2012, 20, 4494-4502. [CrossRef] [PubMed]

4. Kravtsov, V.; Atkin, J.M.; Raschke, M.B. Group delay and dispersion in adiabatic plasmonic nanofocusing. Opt. Lett. 2013, 38, 1322-1324. [CrossRef] [PubMed]

5. Wang, G. Slow light engineering in periodic-stub-assisted plasmonic waveguide. Appl. Opt. 2013, 52, 1799-1804. [CrossRef] [PubMed] 
6. Miyamaru, F.; Morita, H.; Nishiyama, Y.; Nishida, T.; Nakanishi, T.; Kitano, M.; Takeda, M.W. Ultrafast optical control of group delay of narrow-band terahertz waves. Sci. Rep. 2014, 4, 4346. [CrossRef]

7. Dong, Z.-G.; Liu, H.; Cao, J.-X.; Li, T.; Wang, S.-M.; Zhu, S.-N.; Zhang, X. Enhanced sensing performance by the plasmonic analog of electromagnetically induced transparency in active metamaterials. Appl. Phys. Lett. 2010, 97, 114101. [CrossRef]

8. Wang, J.; Fan, C.; He, J.; Ding, P.; Liang, E.; Xue, Q. Double Fano resonances due to interplay of electric and magnetic plasmon modes in planar plasmonic structure with high sensing sensitivity. Opt. Express 2013, 21, 2236-2244. [CrossRef]

9. Fleischhauer, M.; Imamoglu, A.; Marangos, J.P. Electromagnetically induced transparency: Optics in coherent media. Rev. Mod. Phys. 2005, 77, 633-673. [CrossRef]

10. Xu, H.; Li, H.; Liu, Z.; Cao, G.; Wu, C.; Peng, X. Plasmonic EIT switching in ellipsoid tripod structures. Opt. Mater. 2013, 35, 881-886. [CrossRef]

11. Chen, J.; Li, Z.; Zhang, X.; Xiao, J.; Gong, Q. Submicron bidirectional all-optical plasmonic switches. Sci. Rep. 2013, 3, 1451. [CrossRef] [PubMed]

12. Chen, J.; Wang, P.; Chen, C.; Lu, Y.; Ming, H.; Zhan, Q. Plasmonic EIT-like switching in bright-dark-bright plasmon resonators. Opt. Express 2011, 19, 5970-5978. [CrossRef] [PubMed]

13. Liu, N.; Kaiser, S.; Giessen, H. Magnetoinductive and electroinductive coupling in plasmonic metamaterial molecules. Adv. Mater. 2008, 20, 4521-4525. [CrossRef]

14. Zhang, S.; Genov, D.A.; Wang, Y.; Liu, M.; Zhang, X. Plasmon-Induced Transparency in Metamaterials. Phys. Rev. Lett. 2008, 101, 47401. [CrossRef] [PubMed]

15. Jin, X.; Lu, Y.; Zheng, H.; Lee, Y.; Rhee, J.Y.; Jang, W.H. Plasmonic electromagnetically-induced transparency in symmetric structures. Opt. Express 2010, 18, 13396-13401. [CrossRef] [PubMed]

16. Dong, Z.-G.; Liu, H.; Xu, M.-X.; Li, T.; Wang, S.-M.; Zhu, S.-N.; Zhang, X. Plasmonically induced transparent magnetic resonance in a metallic metamaterial composed of asymmetric double bars. Opt. Express 2010, 18, 18229-18234. [CrossRef] [PubMed]

17. Fedotov, V.A.; Rose, M.; Prosvirnin, S.L.; Papasimakis, N.; Zheludev, N.I. Sharp Trapped-Mode Resonances in Planar Metamaterials with a Broken Structural Symmetry. Phys. Rev. Lett. 2007, 99, 147401. [CrossRef] [PubMed]

18. Papasimakis, N.; Fedotov, V.A.; Zheludev, N.I.; Prosvirnin, S.L. Metamaterial Analog of Electromagnetically Induced Transparency. Phys. Rev. Lett. 2008, 101, 253903. [CrossRef] [PubMed]

19. Chiam, S.-Y.; Singh, R.; Rockstuhl, C.; Lederer, F.; Zhang, W.; Bettiol, A.A. Analogue of electromagnetically induced transparency in a terahertz metamaterial. Phys. Rev. B 2009, 80, 153103. [CrossRef]

20. Li, Z.; Ma, Y.; Huang, R.; Singh, R.; Gu, J.; Tian, Z.; Han, J.; Zhang, W. Manipulating the plasmon-induced transparency in terahertz metamaterials. Opt. Express 2011, 19, 8912-8919. [CrossRef]

21. Kekatpure, R.D.; Barnard, E.S.; Cai, W.; Brongersma, M.L. Phase-Coupled Plasmon-Induced Transparency. Phys. Rev. Lett. 2010, 104, 243902. [CrossRef] [PubMed]

22. Liu, N.; Weiss, T.; Mesch, M.; Langguth, L.; Eigenthaler, U.; Hirscher, M.; Sönnichsen, C.; Giessen, H. Planar Metamaterial Analogue of Electromagnetically Induced Transparency for Plasmonic Sensing. Nano Lett. 2010, 10, 1103-1107. [CrossRef] [PubMed]

23. Yang, Y.; Kravchenko, I.I.; Briggs, D.P.; Valentine, J. All-dielectric metasurface analogue of electromagnetically induced transparency. Nat. Commun. 2014, 5, 5753. [CrossRef] [PubMed]

24. Zhang, X.; Xu, N.; Qu, K.; Tian, Z.; Singh, R.; Han, J.; Agarwal, G.S.; Zhang, W. Electromagnetically induced absorption in a three-resonator metasurface system. Sci. Rep. 2015, 5, 10737. [CrossRef] [PubMed]

25. Wang, L.; Gu, Y.; Chen, H.; Zhang, J.-Y.; Cui, Y.; Gerardot, B.D.; Gong, Q. Polarized linewidth-controllable double-trapping electromagnetically induced transparency spectra in a resonant plasmon nanocavity. Sci. Rep. 2013, 3, 2879. [CrossRef] [PubMed]

26. Zhang, Y.; Li, T.; Chen, Q.; Zhang, H.; O'Hara, J.F.; Abele, E.; Taylor, A.J.; Chen, H.-T.; Azad, A.K. Independently tunable dual-band perfect absorber based on graphene at mid-infrared frequencies. Sci. Rep. 2015, 5, 18463. [CrossRef] [PubMed]

27. Wang, J.; Yuan, B.; Fan, C.; He, J.; Ding, P.; Xue, Q.; Liang, E. A novel planar metamaterial design for electromagnetically induced transparency and slow light. Opt. Express 2013, 21, 25159-25166. [CrossRef]

28. Liu, M.; Yin, X.; Ulin-Avila, E.; Geng, B.; Zentgraf, T.; Ju, L.; Wang, F.; Zhang, X. A graphene-based broadband optical modulator. Nature 2011, 474, 64-67. [CrossRef] 
29. Liu, M.; Yin, X.; Zhang, X. Double-Layer Graphene Optical Modulator. Nano Lett. 2012, 12, $1482-1485$. [CrossRef]

30. Liang, G.; Hu, X.; Yu, X.; Shen, Y.; Li, L.H.; Davies, A.G.; Linfield, E.H.; Liang, H.K.; Zhang, Y.; Yu, S.F.; et al. Integrated Terahertz Graphene Modulator with 100\% Modulation Depth. ACS Photonics 2015, 2, 1559-1566. [CrossRef]

31. Mayorov, A.S.; Gorbachev, R.V.; Morozov, S.V.; Britnell, L.; Jalil, R.; Ponomarenko, L.A.; Blake, P.; Novoselov, K.S.; Watanabe, K.; Taniguchi, T.; et al. Micrometer-Scale Ballistic Transport in Encapsulated Graphene at Room Temperature. Nano Lett. 2011, 11, 2396-2399. [CrossRef] [PubMed]

32. Nair, R.R.; Blake, P.; Grigorenko, A.N.; Novoselov, K.S.; Booth, T.J.; Stauber, T.; Peres, N.M.R.; Geim, A.K. Fine Structure Constant Defines Visual Transparency of Graphene. Science 2008, 320, 1308. [CrossRef] [PubMed]

33. Balandin, A.A. Thermal properties of graphene and nanostructured carbon materials. Nat. Mater. 2011, 10, 569-581. [CrossRef] [PubMed]

34. Ju, L.; Geng, B.; Horng, J.; Girit, C.; Martin, M.; Hao, Z.; Bechtel, H.A.; Liang, X.; Zettl, A.; Shen, Y.R.; et al. Graphene plasmonics for tunable terahertz metamaterials. Nat. Nanotechnol. 2011, 6, 630-634. [CrossRef] [PubMed]

35. Lee, S.H.; Choi, M.; Kim, T.-T.; Lee, S.; Liu, M.; Yin, X.; Choi, H.K.; Lee, S.S.; Choi, C.-G.; Choi, S.-Y.; et al. Switching terahertz waves with gate-controlled active graphene metamaterials. Nat. Mater. 2012, 11, 936-941. [CrossRef] [PubMed]

36. Zhang, Y.; Feng, Y.; Zhu, B.; Zhao, J.; Jiang, T. Graphene based tunable metamaterial absorber and polarization modulation in terahertz frequency. Opt. Express 2014, 22, 22743-22752. [CrossRef] [PubMed]

37. Zhang, Y.; Feng, Y.; Zhu, B.; Zhao, J.; Jiang, T. Switchable quarter-wave plate with graphene based metamaterial for broadband terahertz wave manipulation. Opt. Express 2015, 23, 27230-27239. [CrossRef] [PubMed]

38. Xu, B.; Gu, C.; Li, Z.; Niu, Z. A novel structure for tunable terahertz absorber based on graphene. Opt. Express 2013, 21, 23803-23811. [CrossRef] [PubMed]

39. Guo, Y.; Yan, L.; Pan, W.; Luo, B.; Wen, K.; Guo, Z.; Luo, X. Electromagnetically induced transparency (EIT)-like transmission in side-coupled complementary split-ring resonators. Opt. Express 2012, 20, 24348-24355. [CrossRef] [PubMed]

40. Yu, W.; Meng, H.; Chen, Z.; Li, X.; Zhang, X.; Wang, F.; Wei, Z.; Tan, C.; Huang, X.; Li, S. The bright-bright and bright-dark mode coupling-based planar metamaterial for plasmonic EIT-like effect. Opt. Commun. 2018, 414, 29-33. [CrossRef]

41. Chu, H.S.; How Gan, C. Active plasmonic switching at mid-infrared wavelengths with graphene ribbon arrays. Appl. Phys. Lett. 2013, 102, 231107. [CrossRef]

42. Palik, E.D. Handbook of Optical Constants of Solids; Academic Press: Boston, MA, USA, 1998; Volume 3, p. 662.

43. Basu, S.; Lee, B.J.; Zhang, Z.M. Infrared Radiative Properties of Heavily Doped Silicon at Room Temperature. J. Heat Transfer 2009, 132, 23301-23308. [CrossRef]

44. Lao, J.; Tao, J.; Wang, Q.J.; Huang, X.G. Tunable graphene-based plasmonic waveguides: Nano modulators and nano attenuators. Laser Photon. Rev. 2014, 8, 569-574. [CrossRef]

45. Chen, Z.H.; Tao, J.; Gu, J.H.; Li, J.; Hu, D.; Tan, Q.L.; Zhang, F.; Huang, X.G. Tunable metamaterial-induced transparency with gate-controlled on-chip graphene metasurface. Opt. Express 2016, 24, 29216-29225. [CrossRef] [PubMed]

46. Yao, J.; Chen, Y.; Ye, L.; Liu, N.; Cai, G.; Liu, Q.H. Multiple resonant excitations of surface plasmons in a graphene stratified slab by Otto configuration and their independent tuning. Photon. Res. 2017, 5, 377-384. [CrossRef]

47. Gao, W.; Shu, J.; Qiu, C.; Xu, Q. Excitation of Plasmonic Waves in Graphene by Guided-Mode Resonances. ACS Nano 2012, 6, 7806-7813. [CrossRef] [PubMed]

48. Vakil, A.; Engheta, N. Transformation Optics Using Graphene. Science 2011, 332, 1291-1294. [CrossRef] [PubMed]

49. Casiraghi, C.; Hartschuh, A.; Lidorikis, E.; Qian, H.; Harutyunyan, H.; Gokus, T.; Novoselov, K.S.; Ferrari, A.C. Rayleigh Imaging of Graphene and Graphene Layers. Nano Lett. 2007, 7, 2711-2717. [CrossRef]

50. Yan, H.; Li, X.; Chandra, B.; Tulevski, G.; Wu, Y.; Freitag, M.; Zhu, W.; Avouris, P.; Xia, F. Tunable infrared plasmonic devices using graphene/insulator stacks. Nat. Nanotechnol. 2012, 7, 330-334. [CrossRef] 
51. Jain, P.K.; Eustis, S.; El-Sayed, M.A. Plasmon Coupling in Nanorod Assemblies: Optical Absorption, Discrete Dipole Approximation Simulation, and Exciton-Coupling Model. J. Phys. Chem. B 2006, 110, 18243-18253. [CrossRef]

52. Prodan, E.; Nordlander, P. Plasmon hybridization in spherical nanoparticles. J. Chem. Phys. 2004, 120, 5444-5454. [CrossRef] [PubMed]

53. Koh, A.L.; Bao, K.; Khan, I.; Smith, W.E.; Kothleitner, G.; Nordlander, P.; Maier, S.A.; McComb, D.W. Electron Energy-Loss Spectroscopy (EELS) of Surface Plasmons in Single Silver Nanoparticles and Dimers: Influence of Beam Damage and Mapping of Dark Modes. ACS Nano 2009, 3, 3015-3022. [CrossRef] [PubMed]

54. Chen, H.; Shao, L.; Li, Q.; Wang, J. Gold nanorods and their plasmonic properties. Chem. Soc. Rev. 2013, 42, 2679-2724. [CrossRef] [PubMed]

55. Cheng, H.; Chen, S.; Yu, P.; Duan, X.; Xie, B.; Tian, J. Dynamically tunable plasmonically induced transparency in periodically patterned graphene nanostrips. Appl. Phys. Lett. 2013, 103, 203112. [CrossRef]

2018 by the authors. Licensee MDPI, Basel, Switzerland. This article is an open access article distributed under the terms and conditions of the Creative Commons Attribution (CC BY) license (http:/ / creativecommons.org/licenses/by/4.0/). 